\title{
Sex differences in asking for counselling and psychological support from a therapeutic center (A.P.P.A.C.) John Kouros*1,2, Anastasia Karkanis ${ }^{1}$ and Demy Kotta ${ }^{1}$
}

Address: ${ }^{1}$ Association of Psychology \& Psychiatry for Adults \& Children and ${ }^{2}$ Hygeia Hospital, Athens, Greece

* Corresponding author

from International Society on Brain and Behaviour: 3rd International Congress on Brain and Behaviour

Thessaloniki, Greece. 28 November - 2 December 2007

Published: 17 April 2008

Annals of General Psychiatry 2008, 7(Suppl I):S329 doi:I0.II86/I744-859X-7-SI-S329

This abstract is available from: http://www.annals-general-psychiatry.com/content/7/SI/S329

(c) 2008 Kouros et al.; licensee BioMed Central Ltd.

\section{Background}

In the present study, the reasons why people ask for psychological support according to their sex is being investigated.

\section{Materials and methods}

Data was obtained from the Association of Psychology \& Psychiatry for Adults \& Children (A.P.P.A.C.) from January 2002 until December 2006. The sample size was $\mathrm{N}=100$, aged from 22 years to 65 years.

\section{Results}

Results indicated that there were population differences (62 women and 38 men) and statistically significant differences were found in the primary therapeutic goal of clients as well as their therapeutic course, according to their sex.

\section{Conclusions}

More specifically, results indicated that women tend to seek counselling mostly for themselves and secondary for a family member: women aged 25-35 want to deal with personal problems, women aged 35-45 seek for counselling (mostly relationship-based), while women aged 4565 mainly wish to resolve problems with their children. On the other hand, men aged 30-50 years usually require counselling when their symptoms seem to disable them to successfully function in their workplace. Men over 50 years old ask for counselling in order to resolve a problem concerning their children. These men usually end their sessions when symptoms become less severe, while women are found to be more consistent towards therapy.
Finally, as far as their socioeconomic status is concerned research results indicated that men of high socioeconomic status do not easily accept that they need counselling, while women of high socioeconomic status are more receptive towards counselling. 